\title{
Altered respiratory physiology in obesity
}

\author{
Krishnan Parameswaran MD PhD FRCP FCCP, David C Todd MD FRCPC, Mark Soth MD FRCPC
}

K Parameswaran, DC Todd, M Soth. Altered respiratory physiology in obesity. Can Respir J 2006;13(4):203-210.

\section{L'obésité et les modifications de la physiologie respiratoire}

Les principales complications respiratoires de l'obésité sont une demande accrue de ventilation, une augmentation de l'effort respiratoire, l'inefficacité des muscles respiratoires et une diminution de la compliance respiratoire. La diminution de la capacité résiduelle fonctionnelle et du volume de réserve expiratoire ainsi que l'augmentation du rapport du volume de fermeture à la capacité résiduelle fonctionnelle, observées dans l'obésité sont associées à la fermeture des unités de volume respiratoire périphérique, à des anomalies du rapport ventilation-perfusion et à de l'hypoxémie, surtout en position couchée. Cependant, les épreuves habituelles de l'exploration fonctionnelle respiratoire ne sont que légèrement modifiées par les effets de l'obésité, sauf dans les cas extrêmes. De leur côté, les principales complications cardiovasculaires sont une augmentation du volume sanguin total et du volume sanguin pulmonaire, une augmentation du débit cardiaque et une élévation de la pression télédiastolique ventriculaire gauche. Les personnes obèses souffrent souvent d'hypoventilation et d'apnées du sommeil ainsi que d'une diminution de la réactivité respiratoire hypoxémie-hypercapnie. Il en résulte de l'hypoxémie, de l'hypertension pulmonaire et une diminution graduelle de la capacité. Ces personnes présentent également une aggravation de la dyspnée et une diminution de la capacité d'effort, éléments essentiels à la qualité de vie. La diminution de la force musculaire, l'augmentation des douleurs articulaires et le frottement cutané sont des déterminants importants de la diminution de la capacité d'effort, auxquels s'ajoutent les effets cardiopulmonaires de l'obésité. On ne comprend pas encore très bien les effets de l'obésité sur la mortalité attribuable à l'insuffisance cardiaque et aux bronchopneumopathies chroniques obstructives et on ne peut établir avec certitude l'existence d'un lien entre l'obésité et l'asthme et l'hyperréactivité des voies respiratoires. Toutefois, la perte de poids et l'activité physique sont des moyens efficaces de contrer les complications respiratoires de l'obésité.

Key Words: Dyspnea; Exercise testing; Obesity; Pulmonary function tests; Respiratory physiology

and muscle mass. Despite these limitations, the National Institutes of Health's "Clinical guidelines on the identification, evaluation, and treatment of overweight and obesity in adults The evidence report" (2), published in 1998, operationally defined 'overweight' as a BMI of $25 \mathrm{~kg} / \mathrm{m}^{2}$ to $29.9 \mathrm{~kg} / \mathrm{m}^{2}$ and 'obesity' as a BMI of at least $30 \mathrm{~kg} / \mathrm{m}^{2}$. This definition is consistent with recommendations from the World Health Organization and most other countries. Using these guidelines, the prevalence of obesity in Canada has been estimated to be approximately $10 \%$. Worldwide it may range from $2 \%$ to as high as $30 \%$. Urbanization and modernization have powerful effects on the prevalence of overweight and obese individuals in population groups. Secular trends indicate that the prevalence in both adults and children, both nationally and internationally, is likely to increase over the next 10 years. describe the distribution of fat (which may be more predictive of morbidity) (1), nor does it directly measure body composition 


\section{HEALTH HAZARDS OF OBESITY}

Obesity is a major risk factor for many acute and chronic disorders, including cardiovascular and cerebrovascular disease, and diabetes (3). It may worsen many chronic diseases such as hypertension, dyslipidemia, gallstone disease and osteoarthritis. Obesity is associated with additional health conditions including carpal tunnel syndrome, venous insufficiency, deep vein thrombosis and poor wound healing. More recently, health consequences such as nonalcoholic steatohepatitis, menstrual irregularities and infertility, and risk for cancers of the colon, endometrium and breast have been attributed to obesity. Most observational studies have shown a $\mathrm{U}$ - or J-shaped relationship between BMI and mortality, with individuals at very low and very high weights at increased risk, after adjusting for confounding factors such as smoking or preexisting illness. The relationship between low BMI and increased mortality may result from the detrimental effects of lower lean body mass rather than low body weight per se. Not surprisingly, obesity poses a huge economic burden. It is conservatively estimated that the direct cost of obesity in the United States was US $\$ 45.8$ billion in 1990 , while indirect costs totalled US $\$ 23$ billion (4).

Obesity has a profound effect on the physiology of breathing (5). Descriptive reports of the effects of obesity on the cardiopulmonary system first appeared approximately 40 years ago. In brief, obesity can lead to pulmonary compromise in a number of ways, including decreases in respiratory compliance due to mechanical factors such as increased weight on the thoracic cage and abdomen, as well as changes in lung compliance. Over the past 40 years, it has been appreciated that the respiratory system is not universally affected by obesity, and several distinct clinical syndromes have been recognized. At the extremes, these include simple obesity to denote obese subjects with little or no impairment in blood gases or function, and obesity hypoventilation syndrome (OHS) to describe obese patients manifesting alveolar hypoventilation. Severe obesity can lead to OHS and sleep apnea with decreased responsiveness to $\mathrm{CO}_{2}$ and hypoxemia, accompanied by alterations in respiratory muscle function.

The effects of obesity and being overweight on the control of breathing, pulmonary mechanics and the gas exchange mechanism and their consequences on lung function tests and symptoms will be discussed in detail in the following sections.

\section{EFFECTS ON LUNG MECHANICS AND AIRWAY RESISTANCE}

An important respiratory abnormality in obesity is a decrease in total respiratory system compliance, which is supported by the work of Naimark and Cherniack (6). They have demonstrated that total respiratory compliance is reduced by as much as two-thirds of the normal value in obese individuals. This is due, in part, to a decrease in lung compliance that may relate to the increased pulmonary blood volume seen in obese individuals. However, the primary reason is due to a decrease in chest wall compliance associated with the obese individual's accumulation of fat in and around the ribs, the diaphragm and the abdomen. Total respiratory compliance is markedly reduced by recumbency in obese individuals compared with nonobese individuals. This reduction is almost entirely due to the decreased compliance of the chest wall, although it may also be due to an increase in respiratory resistance (7).

Although considerable energy may be spent in overcoming the reduction in chest wall compliance, it accounted for only one-third of the increased work of breathing in the study by Naimark and Cherniack (6). The remaining increase was likely due to an increase in nonelastic work or an inefficiency of the respiratory muscles.

The nonelastic work may have been performed to overcome the air flow limitation and the airway resistance that are reportedly increased in patients with obesity. For example, Rubinstein et al (8) examined the maximum expiratory flow $\left(\mathrm{V}_{\max }\right)$, lung volumes and airway resistance using body plethysmography of 103 obese, lifelong nonsmokers without cardiopulmonary disease and compared them with 190 healthy nonobese nonsmokers. The forced expiratory volume in $1 \mathrm{~s}$ $\left(\mathrm{FEV}_{1}\right)$ of men and women were lower in obese patients compared with nonobese subjects. In addition, the obese men had reduced flow rates at $50 \%$ and $75 \%$ of exhaled vital capacity (VC). The airway resistance was also significantly higher in the obese men. However, the obese men had lower lung volumes compared with the nonobese subjects, and there was no significant difference in the specific conductance or the $\mathrm{V}_{\text {max }}$ at $50 \%$ of VC. Still, the difference in the $\mathrm{V}_{\max }$ at $25 \%$ of $\mathrm{VC}$ persisted. These observations were confirmed by Zerah et al (9) who examined airway resistance in a group of obese subjects that was subdivided into mild, moderate and morbid obesity. Respiratory resistance was estimated by the forced oscillation technique, and the airway resistance was determined by body plethysmography. Both respiratory resistance and airway resistance rose significantly with the level of obesity, which appeared to be inversely related to changes in functional residual capacity (FRC). These findings suggest that in addition to the elastic load, obese individuals must overcome increased airway resistance resulting from a reduction in lung volumes due to obesity.

\section{RESPIRATORY MUSCLES}

Because an obese individual's respiratory muscles must work constantly against a less compliant chest wall and higher airway resistance, it would be expected that they could generate increased pressures. Kelly et al (10) examined the maximum inspiratory and expiratory pressures at different lung volumes in 45 morbidly obese patients, who on average weighed $183 \%$ of their predicted weights. These were compared with the pressures of 25 nonobese age-matched individuals. At all lung volumes, the pressures generated by the obese patients were lower than those of the nonobese patients, despite heightened demands for diaphragmatic work. It is estimated that the maximal voluntary ventilation (MVV), a measurement of respiratory muscle endurance, is reduced by $20 \%$ in healthy obese individuals and by $45 \%$ in obese individuals with OHS $(11,12)$. This may result from diaphragm dysfunction due to increased abdominal and visceral adipose tissue deposition. It has been suggested that the additional load causes a length-tension disadvantage for the diaphragm due to fibre overstretching, which is particularly worse while the individual is supine (13).

\section{OXYGEN COST OF BREATHING}

Oxygen consumption $\left(\mathrm{VO}_{2}\right)$ dedicated to respiratory work during quiet breathing is small in nonobese individuals (less 
than $3 \%$ of the total body $\mathrm{O}_{2}$ consumption). Kress et al (14) examined the $\mathrm{O}_{2}$ consumption of the respiratory system of morbidly obese participants during quiet breathing immediately before gastric bypass surgery and again after intubation, mechanical ventilation and paralysis. Baseline $\mathrm{VO}_{2}$ was higher in the obese patients compared with the control subjects; however, when standardized for BMI, it was significantly lower than that of the control patients. There was a significant reduction in the $\mathrm{VO}_{2}$ from spontaneous breathing to mechanical ventilation in the obese patients $(16 \%)$ but not in the control subjects $(1 \%)$. The lower $\mathrm{VO}_{2}$ standardized to body size did not ameliorate the detrimental impact of morbid obesity on the $\mathrm{O}_{2}$ cost of breathing. This suggests that morbidly obese patients dedicate a disproportionately high percentage of total $\mathrm{VO}_{2}$ for respiratory work, even during quiet breathing. This relative inefficiency suggests a decreased ventilatory reserve and a predisposition to respiratory failure in the setting of even mild pulmonary or systemic insults. Other estimates of the work of breathing and $\mathrm{O}_{2}$ costs have been estimated to be $70 \%$ higher and four times greater than normal, respectively (12).

\section{EFFECTS ON PULMONARY FUNCTION}

Obese individuals tend to have a rapid, shallow breathing pattern, which is also seen in patients with neuromuscular disorders and deformities of the chest wall. As explained above, the $\mathrm{O}_{2}$ cost of breathing is less for a given ventilation when the respiratory rate is high and the tidal volume $\left(\mathrm{V}_{\mathrm{T}}\right)$ is small. Yet, because the $\mathrm{O}_{2}$ cost of breathing rises parabolically with the respiratory rate and because the relative dead space $\left(\mathrm{V}_{\mathrm{D}} / \mathrm{V}_{\mathrm{T}}\right)$ increases, rapid breathing ultimately is uneconomical. This may explain why obese individuals commonly perform poorly on pulmonary function tests that require high levels of breathing effort, such as the MVV.

\section{Static lung volumes}

The most common pulmonary function abnormality in obese subjects is a reduction in the expiratory reserve volume (ERV) (11). This occurs because the mass loading effect of obesity decreases FRC. Because FRC is reduced and the residual volume (RV) is not, ERV declines. ERV reduction is greatest in the supine position when the diaphragm ascends in the chest, and the weight of the lower thorax and the abdomen is applied to the lungs. At this point, the ERV may approach or be exceeded by the closing volume and gas may be trapped in the chest. The mechanism of regional gas trapping in obesity was first demonstrated by Caro et al (15), who strapped the chest walls of nonobese subjects with adhesive tape, rubber tubing and adjustable corsets. They found that strapping reduced chest wall compliance and prompted the rapid, shallow breathing pattern observed in obesity. Strapping also reduced FRC and ERV and created a delay in the wash-out of nitrogen from the lungs of subjects breathing $100 \% \mathrm{O}_{2}$. This delay was caused by the nitrogen trapping in poorly ventilated lung units due to small airway closure and subsequent atelectasis, and correlated with a fall in the partial pressure of $\mathrm{O}_{2}$ in arterial blood $\left(\mathrm{PaO}_{2}\right)$. Subsequent investigations evaluating the effect of chest wall strapping confirmed the effect on static lung volumes, but also demonstrated that the increase in lung elastic recoil was not entirely explained by airway closure and subsequent atelectasis (16). The exact mechanism to explain this remains elusive.

\section{Dynamic lung volumes}

While the decrease in ERV and FRC are proportionate to the degree of obesity, dynamic lung volumes including $\mathrm{VC}$ and total lung capacity (TLC) are often normal $(11,17)$. In a study of 43 obese but otherwise healthy nonsmoking young adults, Ray et al (11) observed that the lung function of most individuals was within the generally accepted $95 \%$ confidence limits for the predicted values. In a retrospective study (18) evaluating lung function in morbidly obese individuals (defined as a body weight [in kilograms] divided by height [in centimetres] greater than $0.9 \mathrm{~kg} / \mathrm{cm}$ ), $\mathrm{VC}$ was reduced to $75 \%$ of the predicted value while TLC remained within normal limits. Therefore, an abnormal measurement of these lung volumes is likely due to intrinsic lung disease and not obesity, except possibly in those with morbid obesity. These changes have been demonstrated to reverse with weight loss (19).

Similar effects of obesity have also been examined in children between the ages of eight and 15 years (20). When compared with predicted normal values for sex, height and body surface area, decreases were observed in ERV, FEV 1 , forced expiratory flow (FEF) from $25 \%$ to $75 \%$ and MV; RV, the RV to TLC ratio, minute ventilation and the resting energy expenditure were elevated.

\section{Spirometric measurements}

Generally, in mild obesity, spirometry is normal. As BMI increases (particularly in morbidly obese individuals) there is evidence of a reduction in expiratory flow and a decrease in $\mathrm{FEV}_{1}$ and forced vital capacity (FVC) (11). In a study by Sahebjami and Gartside (21), reductions in $\mathrm{FEV}_{1}, \mathrm{FVC}$ and maximal inspiratory flow rate in obese subjects were associated with a low MVV. Both FEV 1 and FVC were similarly reduced (in terms of percentage predicted), the $\mathrm{FEV}_{1}$ to $\mathrm{FVC}$ ratio was normal and static lung volumes were reduced, suggesting the reduction may be due to restriction as opposed to air flow obstruction. Lazarus et al (22) found that the $\mathrm{FEV}_{1}$ to FVC ratio decreases with increasing BMI in overweight and obese individuals. In morbidly obese subjects (defined as individuals with a body weight (in kilograms) to height (in centimetres) ratio greater than $0.9 \mathrm{~kg} / \mathrm{cm}$ ), Biring et al (18) found a reduction in midexpiratory flows and the $\mathrm{FEV}_{1}$ to $\mathrm{FVC}$ ratio.

Therefore, it appears that spirometric abnormalities in patients with mild to moderate obesity represent a restrictive defect placed on the system whereas with severe and morbid obesity, it represents true air flow obstruction. The mechanism may be related to small airway collapse due to decreased lung volumes with increasing obesity or it may be independent.

\section{DISTRIBUTION OF FAT AND EFFECT ON LUNG FUNCTION}

The pattern of body fat distribution may also influence the effect of obesity on lung function. It is generally believed that upper body obesity carries a higher risk of cardiovascular and metabolic disease than lower body obesity. Collins et al (23) demonstrated that multiple measures of adiposity showed a significant inverse relationship with both spirometry and static lung volumes. The best measure of fat distribution was the biceps skinfold, which is a measure of upper body fat distribution. Another study (22) showed that the ratio of abdominal circumference to hip breadth and subscapular skinfold thickness were negatively associated with $\mathrm{FEV}_{1}$ and FVC. This suggests that central abdominal obesity has a 
greater impact on spirometric measures compared with back or lower body obesity. This relationship appeared to diminish with age. Despite these findings, confirmation in nonsmoking men and women with a more ethnically and anthropologically diverse population is warranted.

\section{EFFECTS ON GAS EXCHANGE}

Gas exchange is usually assessed by the carbon monoxide diffusion capacity $\left(\mathrm{DL}_{\mathrm{CO}}\right)$. Ray et al (11) observed that both $\mathrm{DL}_{\mathrm{CO}}$ and the ratio of $\mathrm{DL}_{\mathrm{CO}}$ to alveolar volume increased with increasing obesity. These are reversed with weight loss. This increase is thought to be due to an increase in pulmonary blood volume. The $\mathrm{DL}_{\mathrm{CO}}$ is dependent on pulmonary blood volume, but only to the extent that there may be increased pulmonary vascular recruitment with increased flow. Thus, although cardiac output may be elevated in obesity, the increase in $\mathrm{DL}_{\mathrm{CO}}$ likely results from increased pulmonary blood volume and flow. This increase has been observed without evidence of pulmonary congestion or heart disease. The $\mathrm{DL}_{\mathrm{CO}}$ is directly related to the lung volume at which it is measured and any tendency toward reduced lung volumes with obesity will decrease $\mathrm{DL}_{\mathrm{CO}}$. Therefore, in contrast to other pulmonary function tests, with $\mathrm{DL}_{\mathrm{CO}}$, the expected $\mathrm{DL}_{\mathrm{CO}}$ values in otherwise healthy obese subjects are higher than predicted. A low to normal $\mathrm{DL}_{\mathrm{CO}}$ or the ratio of $\mathrm{DL}_{\mathrm{CO}}$ to alveolar volume in obesity may represent a loss of pulmonary capillary bed (as seen with atelectasis), especially at high BMIs.

\section{VENTILATION AND PERFUSION}

Regional distributions of both ventilation and lung volume are altered by factors such as age, posture and body weight. In nonobese subjects, in both the seated and the lateral decubitus positions, ventilation (normalized for lung volume) is greatest in the dependent lung zones and decreases toward the nondependent lung zones. This relationship is altered in some obese subjects. Holley et al (24), in the mid-1960s, studied lung ventilation and perfusion in eight obese subjects using radioactive xenon. In four subjects in whom the ERV averaged $49 \%$ of the predicted value, the ventilation distribution measured with xenon-133 was normal. In the other four subjects, in whom the ERV was reduced to $21 \%$ of the predicted value, the distribution of a normal tidal breath was predominantly to the upper zones. In all subjects, the perfusion was predominantly to the lower lung zones, but was slightly more uniform than in healthy nonobese subjects. During tidal volume breathing, the ventilation and perfusion distribution were normal in four subjects, whereas in the remaining four, perfusion was maximal in the lower zones to which ventilation was significantly reduced. These findings suggest that there may be significant ventilation to perfusion ratio abnormality on a regional basis in obese individuals that appears to bear a close relationship to the degree of reduction in ERV. The mechanism responsible for underventilation at the bases is thought to be secondary to airway closure and alveolar collapse (atelectasis). These observations have since been confirmed in the lateral decubitus position as well (25).

\section{CONTROL OF BREATHING}

\section{Alveolar hypoventilation}

Although many obese patients are hypoxemic, mildly obese patients are able to eliminate rising levels of $\mathrm{CO}_{2}$ in the blood that occur during $\mathrm{CO}_{2}$ rebreathing and during exercise. However, some obese patients, usually the morbidly obese, fail to increase their minute ventilation when stressed and may even be hypercapnic at rest. This is the OHS that was observed and very elegantly described by Charles Dickens in his character "fat boy Joe" in The Pickwick Papers. Subsequently, these patients develop polycythemia, periodic respiration with apneic pauses during sleep, pulmonary hypertension and cardiac failure.

These abnormalities were initially attributed to the mechanical limitations and decreased chest compliance preventing adequate ventilation. Although Sharp et al (26) had demonstrated a decrease in thoracic compliance associated with obesity, this did not improve in patients with OHS when they reduced their weight. Furthermore, although $V_{D} / V_{T}$ was increased in some of the subjects with OHS reported by Kaufman et al (27), the $\mathrm{V}_{\mathrm{D}} / \mathrm{V}_{\mathrm{T}}$ did not correlate with the patient's resting $\mathrm{PaCO}_{2}$. Subsequently, Gilbert et al (28), who measured the response to $\mathrm{CO}_{2}$ inhalation in 26 subjects who were at least $40 \%$ over ideal body weight, determined that subjects with OHS differed from those with simple obesity solely on the basis of their ventilatory response to $\mathrm{CO}_{2}$ and not in terms of weight or other clinical parameters. Leech et al (29) have shown the degree of $\mathrm{PaCO}_{2}$ elevation is inversely related to $\mathrm{FEV}_{1}$, which suggests abnormal respiratory mechanics may, in part, be responsible. Other mechanisms may include respiratory muscle weakness or inefficiency, impaired central drive, increased inspiratory threshold or abnormal ventilatory load compensation and increased work of breathing (12). Further investigation to elucidate the mechanism responsible for this effect is required.

In addition to hypoventilation, patients with obesity may exhibit periodic apneic or hypopneic episodes during sleep, known as sleep apnea syndrome (30). Central sleep apnea is the cessation of air flow accompanied by a lack of respiratory muscle movements, whereas obstructive sleep apnea (OSA) is the absence of air flow despite the presence of respiratory movements. A combination of central and obstructive sleep apnea may also be observed. Both OHS and sleep apnea share many common physiological and pathological features. However, it has recently been recognized that OSA may also occur in the absence of obesity.

The resultant hypoxia can lead to pulmonary vasoconstriction and pulmonary hypertension (31). Elevations in pulmonary artery pressure, measured using pulmonary artery catheterization, have been observed in approximately $27 \%$ of patients with OSA without any comorbidity. Nocturnal desaturation likely leads to remodelling and restructuring of the walls of the pulmonary arterioles, resulting in permanent daytime pulmonary hypertension. This has been demonstrated in rats submitted to intermittent hypoxia for $4 \mathrm{~h}$ to $8 \mathrm{~h}$ per day (32).

\section{VENTILATORY RESPONSIVENESS}

The evidence that an abnormal ventilatory drive is involved in the pathogenesis of OHS comes from several sources. One of the most important initial observations was a reduction in $\mathrm{PaCO}_{2}$ in OHS patients following the administration of progesterone through its effect as a respiratory stimulant (33). Although it is now well recognized that patients with OHS have diminished ventilatory responsiveness, it is not certain whether this precedes obesity or is acquired. Emirgil and Sobol (19) did not observe an improvement in $\mathrm{CO}_{2}$ responsiveness 
in a group of obese subjects following weight reduction and suggested that the blunted responsiveness precedes obesity. However, Fried et al (34) demonstrated that $\mathrm{CO}_{2}$ sensitivity could be improved with dietary manipulation, resulting in a metabolic state that utilizes ketone bodies as the principal energy substrate of the brain. Zwillich et al (35) have observed that in patients with OHS, the hypoxic drive was one-sixth and the hypercapnic drive was one-third that of nonobese subjects. They also suggested an inherited basis for this blunted effect. This remains to be confirmed.

\section{EFFECTS ON EXERCISE PHYSIOLOGY}

Obesity is associated with increased exertional dyspnea and lower 6 min walk distances in healthy subjects (36). Volitional exercise capacity is frequently affected by discomfort from pain due to increased load on the feet and joints, as well as from skin friction from the rubbing of obese limbs (36). Furthermore, obesity imposes additional stress to ventilation during exercise as a direct result of the increased body mass requiring greater metabolic energy exchange and secondary functional impairment as a result of altered pulmonary function (37).

Obesity has a detrimental effect on $\mathrm{O}_{2}$ uptake both at rest and with exertion. At rest, the baseline $\mathrm{VO}_{2}$ is approximately $25 \%$ greater than the $\mathrm{VO}_{2}$ for nonobese individuals (12). Peak $\mathrm{O}_{2}$ uptake adjusted for true body weight is reduced, although it is usually normal when adjusted for ideal body weight. Generally, there is evidence of a reduction in achieved workload accompanied by work inefficiency, with an increase in $\mathrm{VO}_{2}$ for a given workload (38). Therefore, although the slope of the $\mathrm{VO}_{2}$ work-rate relationship is unchanged, it does appear to be shifted upwards. This response may vary depending upon whether testing is performed using a cycle ergometer or a treadmill (in which additional work will be performed to carry the individual's weight). Other responses may vary depending upon the severity of obesity. In moderately obese persons, parameters including peak $\mathrm{O}_{2}$ pulse $\left(\mathrm{VO}_{2} /\right.$ heart rate $\left.[\mathrm{HR}]\right)$, peak $\mathrm{VO}_{2}$ and anaerobic threshold are normal (39). The breathing pattern observed during exercise is similar to that at rest, with a rapid, shallow breathing pattern (40). This is predominantly due to the mechanical constraints (increased elastic load) placed on the chest wall from excessive adipose tissue deposition. Despite the abnormalities imposed on the respiratory system, it is unusual for obese individuals to demonstrate ventilatory limitation based on traditional measures used to determine ventilatory reserve (such as the difference between MVV and a given ventilation achieved at peak exercise). Other less widely used methods of evaluating ventilatory limitation, including exercise tidal flow-volume loop analysis, indicate that breathing at low lung volumes prevents the normal decrease in end-expiratory lung volume during exercise and may be associated with expiratory flow limitation and subsequent ventilatory constraint $(39,41)$. Although dead space ventilation may be increased at rest, it usually responds normally with a decrease toward the normal range with exercise $(38,42)$. The resting HR is usually elevated, reflecting an increase in cardiac output at rest. With exercise, there is a normal $\mathrm{HR}-\mathrm{VO}_{2}$ relationship reflected by a normal $\mathrm{HR}-\mathrm{VO}_{2}$ slope and attainment of the predicted $\mathrm{HR}$ with no $\mathrm{HR}$ reserve.

\section{EFFECTS ON CARDIOVASCULAR FUNCTION}

Although most studies evaluating the effect of obesity on hemodynamic measures have involved morbidly obese patients, its association with increases in stroke volume, cardiac output, left ventricular end-diastolic pressure and pulmonary artery pressure are well recognized $(43,44)$. The hypervolemic and hyperdynamic states increase left ventricular work and lead to an increase in cardiac mass that is proportional to the degree of obesity (45). The increase in heart mass is predominantly due to an increase in muscle mass of the left ventricle and not due to epicardial or myocardial fat infiltration. Growing evidence $(46,47)$ suggests that the eccentric hypertrophy of the left ventricle secondary to obesity is also associated with subclinical left ventricular diastolic dysfunction. Echocardiographic studies have shown prolonged isovolemic relaxation time, higher peak atrial velocity, and lower ratios of peak early to atrial filling velocity, which are all consistent with diastolic dysfunction (48). This has been confirmed in both men and women (49), and appears to depend on the degree of obesity. This has implications for the respirologist because obese patients frequently experience symptoms of dyspnea that could be due to diastolic dysfunction.

Although the prevalence of systolic dysfunction in healthy obese patients is similar compared with that in lean individuals (47), there is an increased risk of cardiovascular disease including coronary artery disease and congestive heart failure (50). Recent data have suggested that obesity may have a 'paradoxical effect' on survival in patients with chronic, stable heart failure (51). When data from the Digitalis Investigation Group trial were evaluated to assess the impact of obesity on heart failure outcomes, Curtis et al (51) found a lower mortality (allcause and cardiovascular death) rate as BMI increased. There appeared to be levelling off at a BMI of $35 \mathrm{~kg} / \mathrm{m}^{2}$ in which no additional reduction in mortality was observed. The mechanism behind this effect remains to be established, but may reflect a close relation to BMI and muscle mass at lower BMI, which is lost in very obese patients, as seen in obese chronic obstructive pulmonary disease (COPD) patients (52).

Pulmonary blood volume is also increased and is accommodated by recruitment of previously underperfused vessels, perhaps contributing to the decrease in lung compliance. An increase in pulmonary blood volume may also contribute in part to pulmonary arterial hypertension. Weyman et al (53) used echocardiography to evaluate five large cohorts of predominantly obese healthy women for the presence of pulmonary arterial hypertension. They found an elevated systolic pulmonary artery pressure of greater than $35 \mathrm{mmHg}$ in $24 \%$ of all subjects. Elevations in pulmonary artery pressure were more likely to be associated with increasing age and BMI.

\section{OBESITY AND DYSPNEA}

Breathlessness on exertion is a very common symptom in obese individuals (54), and has been reported in almost $80 \%$ of subjects. In another study (55) of obese patients with type II diabetes mellitus, one-third reported abnormal breathing that became more prevalent with increasing BMI. The cause of dyspnea in these patients was likely due to a variety of factors related to the abnormal physiological effects of being overweight and the obesity itself, and to comorbidity related to obesity such as diastolic dysfunction, coronary artery disease, pulmonary hypertension and gastroesophageal reflux disease. In healthy obese subjects, the sensation of dyspnea may originate from an increase in the work of breathing to overcome decreases in pulmonary compliance and increases in resistance. Airway obstruction at low lung volumes may also stimulate 


\section{TABLE 1}

\section{Respiratory consequences of obesity}

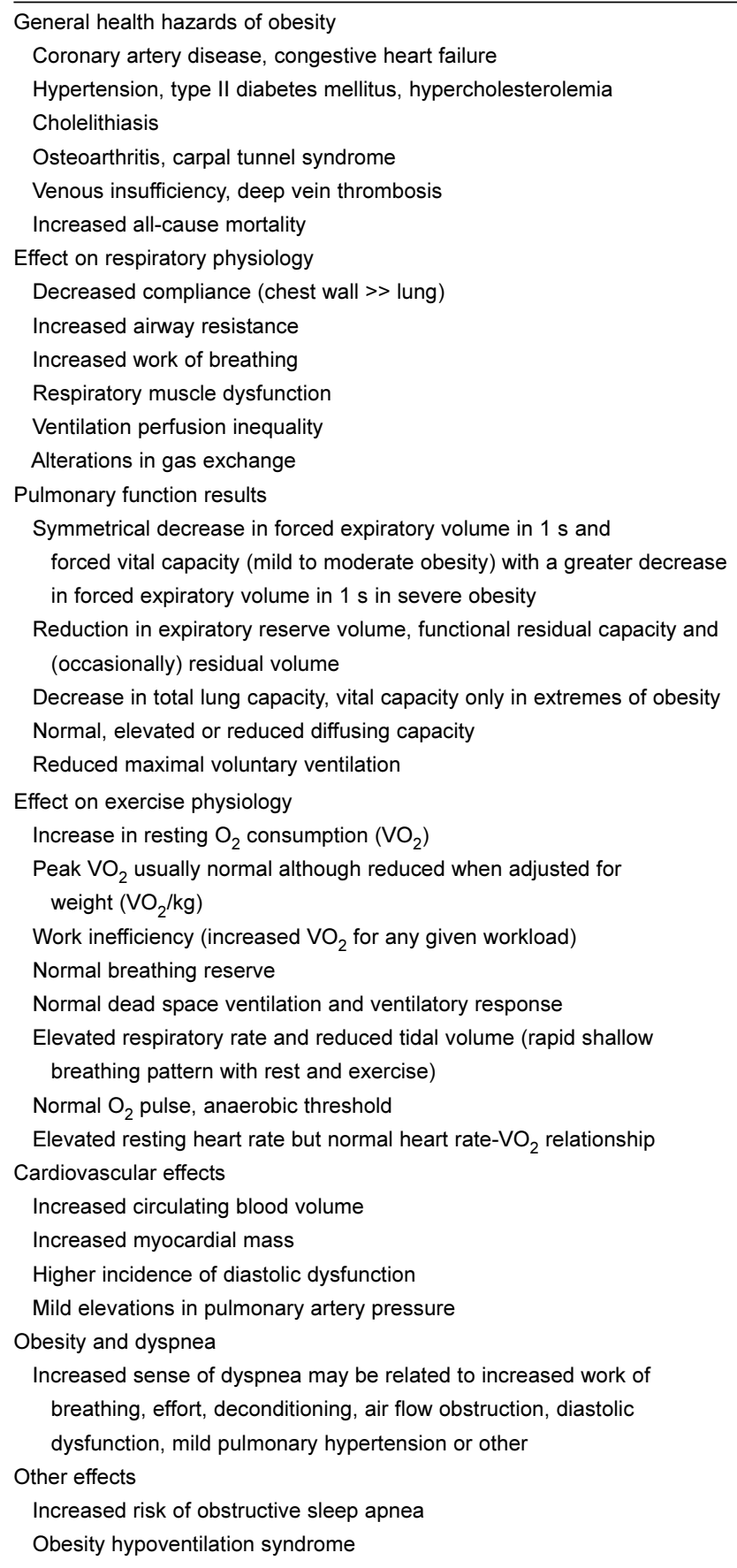

flow receptors to increase the sensation of breathlessness $(56,57)$. Respiratory muscle weakness and fatigue may lead to dyspnea through an increase in effort (sensed in the somatosensory cortex) and chemoreceptor activity responding to increasing $\mathrm{CO}_{2}$ production and hydrogen ion release. There is evidence that healthy obese individuals with a normal FEV and $\mathrm{FEV}_{1}$ to $\mathrm{FVC}$ ratio are more likely to experience dyspnea at rest with increasing BMI, reduced maximum expiratory mouth pressure, reduced MVV and peripheral airway obstruction (as measured by $\mathrm{FEF}_{75}$ ) compared with obese individuals without dyspnea (57)
Morbidly obese subjects with orthopnea may have a greater reduction in expiratory flow and ERV when supine compared with those without orthopnea (58). The dyspnea associated with assuming the supine position may be related to the development of intrinsic positive end-expiratory pressure and dynamic hyperinflation from increased expiratory flow limitation.

\section{OBESITY AND OBSTRUCTIVE LUNG DISEASE}

There are data to suggest that obesity is a risk factor for obstructive lung disease, including asthma (59-62), which may be related to smaller airway calibre at low lung volumes, and increased airway hyperresponsiveness (AHR) seen with airway narrowing (63) and absence of the bronchoprotective effect of deep inhalations (64). Obesity may also induce airway reactivity by immunological mechanisms. Both human adipose tissue and macrophages from leptin-deficient obese mice produce interleukin (IL)-6 and cyclooxygenase-2, which are induced in tandem; IL- 6 and the cyclooxygenase- 2 product prostaglandin $E_{2}$ promote humoral immunity, and prostaglandin $\mathrm{E}_{2}$ promotes $\mathrm{Th} 2$ cytokine responses such as IL-4, IL-5 and IL-13, which are associated with asthmatic inflammation. Thus, in obese individuals, the biological activity of adipose tissue may increase the risk for developing asthma and AHR (65). Despite this, a causal relationship has not been established, and a more recent study by Sin et al (66) has provided evidence refuting the relationship between asthma and obesity. They reviewed the data of over 16,000 patients from the Third National Health and Nutrition Examination Survey (NHANES III) to assess whether increasing BMI is associated with obstructive lung disease (using spirometry), bronchodilator use and self-reported asthma. Although selfreported asthma, dyspnea and bronchodilator use increased with increasing BMI, there was no increase in the prevalence of air flow obstruction. This suggests that dyspnea in obesity may be due to causes other than asthma. Other studies have reached similar conclusions, but further prospective data are required that include measures of AHR and air flow reversibility $(67,68)$. Although there may be a relationship between asthma and obesity, objective confirmation of the diagnosis is required to avoid overtreatment and the risk of missing an alternate etiology for symptoms of dyspnea.

The interaction between obesity and COPD has not been resolved. A BMI in the obese range has been associated with decreased respiratory-related deaths in COPD patients, but there is no physiological explanation for this (69). This observation may be due to a decrease in $\mathrm{FEV}_{1}$ that is, in part, attributable to obesity, rather than intrinsic lung disease, thereby leading to a misclassification of the severity of COPD. Low BMI has been associated with increased mortality in COPD, although it loses its predictive capability when adjusted for muscle mass (70). Maximum exercise capacity is a strong predictor of mortality in COPD, independent of age or FEV (71). Soth et al (52) examined the maximum exercise capacity in 2625 patients with COPD, including 450 obese patients, using cycle ergometry. Maximum exercise capacity increased with increasing BMI but declined as the BMI increased into the obese range. This was largely due to decreased breathing capacity and leg strength in obese subjects. When these parameters, along with age, $\mathrm{DL}_{\mathrm{CO}}$ and sex, were accounted for, BMI no longer had an effect on exercise capacity. A study examining mortality in obese COPD patients that measures muscle mass or 
strength and $\mathrm{DL}_{\mathrm{CO}}$, in addition to $\mathrm{FEV}_{1}$, may refute the suggestion that obesity is protective in COPD patients.

\section{EFFECT OF WEIGHT LOSS AND PHYSICAL ACTIVITY}

Because most of the respiratory function abnormalities seen in obesity are due to the mechanical load of adipose tissue on the chest wall and resultant deconditioning, it would be expected that a reduction in weight would lead to improvement in many of these physiological derangements. Following weight reduction (bariatric) surgery, there is improvement in RV, ERV, FRC and TLC (although to a lesser degree) that is attributed to improvement in pulmonary mechanics following removal of the restrictive load (72). Data from the Swedish Obese Subjects study (73) provide further evidence of the beneficial effects of weight reduction on symptoms associated with obesity. In a nonrandomized, controlled study of over 2000 patients, they demonstrated that bariatric surgery (with an average sustained weight loss of $28 \mathrm{~kg}$ ) resulted in a reduction in symptoms of dyspnea and chest pain, and an increase in time spent in physical activity over a two-year period (73). Individuals with the greatest degree of weight reduction benefitted the most. There is less evidence for the respiratory benefits of nonsurgically induced weight reduction (given the difficulty in losing and maintaining weight), although a similar benefit should be expected (74).

\section{SUMMARY}

The major respiratory complications of obesity with or without hypoventilation include a heightened demand for ventilation, elevated work of breathing, respiratory muscle inefficiency and diminished respiratory compliance (Table 1). The decreased FRC and ERV with a high closing volume to FRC ratio of obesity are associated with the closure of peripheral lung units, ventilation to perfusion ratio abnormalities and hypoxemia, especially in the supine position. Conventional respiratory function tests are only mildly affected by obesity unless it is extreme. The major circulatory complications are an increased total and pulmonary blood volume, a high cardiac output and elevated left ventricular end-diastolic pressure. Patients with obesity commonly develop hypoventilation and sleep apnea syndromes with attenuated hypoxic and hypercapnic ventilatory responsiveness. The final result is increasing hypoxemia, pulmonary hypertension and progressively worsening disability. Obese patients have increased dyspnea and decreased exercise capacity, which are vital to quality of life. Decreased muscle, increased joint pain, and skin friction are important determinants of decreased exercise capacity in addition to the cardiopulmonary effects of obesity. The effects of obesity on mortality in heart failure and COPD have not been definitively resolved. Whether obesity contributes to asthma and AHR is uncertain. Weight reduction and physical activity are effective means of reversing the respiratory complications of obesity.

ACKNOWLEDGEMENTS: Dr Krishnan Parameswaran is supported by a clinician-scientist award from the Canadian Institutes of Health Research. The authors thank Dr Mark Inman, McMaster University, Hamilton, Ontario, for his helpful comments.

\section{REFERENCES}

1. Yusuf S, Hawken S, Ounpuu S, et al; INTERHEART Study Investigators. Obesity and the risk of myocardial infarction in 27,000 participants from 52 countries: A case-control study. Lancet 2005;366:1640-9.

2. National Institutes of Health. Clinical guidelines on the identification, evaluation, and treatment of overweight and obesity in adults - The evidence report. National Institutes of Health. Obes Res 1998;6(Suppl 2):51S-209S.

3. National Task Force on the Prevention and Treatment of Obesity. Overweight, obesity and health risk. Arch Intern Med 2000;160:898-904.

4. Bjorntorp P, VanItallie TB. Introduction: The medical cost of obesity. Pharmacoeconomics 1994;5(Suppl 1):33.

5. Luce JM. Respiratory complications of obesity. Chest 1980;78:626-30.

6. Naimark A, Cherniack RM. Compliance of the respiratory system and its components in health and obesity. J Appl Physiol 1960;15:377-82.

7. Yap JC, Watson RA, Gilbey S, Pride NB. Effects of posture on respiratory mechanics in obesity. J Appl Physiol 1995;79:1199-205.

8. Rubinstein I, Zamel N, DuBarry L, Hoffstein V. Airflow limitation in morbidly obese nonsmoking men. Ann Intern Med 1990;112:828-32.

9. Zerah F, Harf A, Perlemuter L, Lorino H, Lorino AM, Atlan G. Effects of obesity on respiratory resistance. Chest 1993;103:1470-6.

10. Kelly TM, Jensen RL, Elliott CG, Crapo RO. Maximum respiratory pressures in morbidly obese subjects. Respiration 1988;54:73-7.

11. Ray CS, Sue DY, Bray G, Hansen JE, Wasserman K. Effects of obesity on respiratory function. Am Rev Respir Dis 1983;128:501-6.

12. Koenig SM. Pulmonary complications of obesity. Am J Med Sci 2001;321:249-79.

13. Sharp JT, Druz WS, Kondragunta VR. Diaphragmatic response to body position changes in obese patients with obstructive sleep apnea. Am Rev Respir Dis 1986;133:32-7.

14. Kress JP, Pohlman AS, Alverdy J, Hall JB. The impact of morbid obesity on oxygen cost of breathing at rest. Am J Respir Crit Care Med 1999;160:883-6.

15. Caro CG, Butler J, DuBois AB. Some effects of restriction of chest cage expansion on pulmonary function in man: An experimental study. J Clin Invest 1960;39:573-83.

16. Klineberg PL, Rehder K, Hyatt RE. Pulmonary mechanics and gas exchange in seated normal men with chest restriction. J Appl Physiol 1981;51:26-32.

17. Jenkins SC, Moxham J. The effects of mild obesity on lung function. Respir Med 1991;85:309-11.

18. Biring MS, Lewis MI, Liu JT, Mohsenifar Z. Pulmonary physiologic changes of morbid obesity. Am J Med Sci 1999;318:293-7.

19. Emirgil C, Sobol BJ. The effects of weight reduction on pulmonary function and the sensitivity of the respiratory centre in obesity. Am Rev Respir Dis 1973;108:831-42.

20. Inselma LS, Milanese A, Deurloo A. Effect of obesity on pulmonary function in children. Pediatr Pulmonol 1993;16:130-7.

21. Sahebjami H, Gartside PS. Pulmonary function in obese subjects with a normal $\mathrm{FEV}_{1} / \mathrm{FVC}$ ratio. Chest 1996;110:1425-9.

22. Lazarus R, Sparrow D, Weiss ST. Effects of obesity and fat distribution on ventilatory function. Chest 1997;111:891-8.

23. Collins LC, Hoberty PD, Walker JF, Fletcher EC, Peiris AN. The effect of body fat distribution on pulmonary function tests. Chest 1995;107:1298-302.

24. Holley HS, Milic-Emili J, Becklake MR, Bates DV. Regional distribution of pulmonary ventilation and perfusion in obesity. J Clin Invest 1967;46:475-81.

25. Hurewitz AN, Susskind H, Harold WH. Obesity alters regional ventilation in lateral decubitus position. J Appl Physiol $1985 ; 59: 774-83$. 
26. Sharp JT, Henry JP, Sweany SK, Meadows WR, Pietras RJ. The total work of breathing in normal and obese men. J Clin Invest 1964:48:728-39.

27. Kaufman BJ, Ferguson MH, Cherniack RM. Hypoventilation in obesity. J Clin Invest 1959;38:500-11.

28. Gilbert R, Sipple JH, Auchincloss JH. Respiratory control and work of breathing in obese subjects. J Appl Physiol 1961;16:21-6.

29. Leech J, Onal E, Aronson R, Lopata M. Voluntary hyperventilation in obesity hypoventilation. Chest 1991;100:1334-8.

30. Guilleminault C, Tilkian A, Dement WC. The sleep apnoea syndrome. Ann Rev Med 1976;27:465-84.

31. Bady E, Achkar A, Pascal S, Orvoen-Frija E, Laaban JP. Pulmonary arterial hypertension in patients with sleep apnoea syndrome. Thorax 2000;55:934-9.

32. Kay JM, Suyama KL, Keane PM. Effect of intermittent normoxia on muscularization of pulmonary arterioles induced by chronic hypoxia in rats. Am Rev Respir Dis 1981;123:454-8.

33. Lyons HH, Huang CT. Therapeutic use of progesterone in alveolar hypoventilation associated with obesity. Am J Med 1968;44:881-8.

34. Fried PI, McClean PA, Phillipaon EA, Zamel N, Murray FT, Marliss EB. Effect of ketosis on respiratory sensitivity to carbon dioxide in obesity. N Engl J Med 1976;294:1081-6.

35. Zwillich CW, Sutton FD, Pierson DJ, Greagh EM, Weil JV. Decreased hypoxic ventilatory drive in the obesity-hypoventilation syndrome. Am J Med 1975;59:343-8.

36. Hulens M, Vansant G, Claessens AL, Lysens R, Muls E. Predictors of 6-minute walk test results in lean, obese and morbidly obese women. Scand J Med Sci Sports 2003;113:98-105.

37. Whipp BJ, Davis JA. The ventilatory stress of exercise in obesity. Am Rev Respir Dis 1984;129(Suppl):S90-S2.

38. Dempsey JA, Reddan W, Balke B, Rankin J. Work capacity determinants and physiologic cost of weight-supported breathing in obesity. J Appl Physiol 1966;21:1815-20.

39. American Thoracic Society/American College of Chest Physicians Joint Committee. ATS/ACCP Statement on cardiopulmonary exercise testing. Am J Respir Crit Care Med 2003;167:211-77.

40. Sakamoto S, Ishikawa K, Senda S, Nakajima S, Matsuo H. The effect of obesity on ventilatory response and anaerobic threshold during exercise. J Med Syst 1993;17:227-31.

41. Johnson BD, Weisman IM, Zeballos RJ, Beck KC. Emerging concepts in the evaluation of ventilatory limitation during exercise: The exercise tidal flow-volume loop. Chest 1999;116:488-503.

42. Dempsey JA, Reddan W, Rankin J, Balke B. Alveolar-arterial gas exchange during muscular work in obesity. J Appl Physiol 1966;21:1807-14.

43. Alpert MA, Hashimi MW. Obesity and the heart. Am J Med Sci 1993;306:117-23.

44. De Divitiis O, Fazio S, Pettito M. Obesity and cardiac function. Circulation 1981;64:477-82.

45. Amad KH, Brennan JC, Alexander JK. The cardiac pathology of chronic exogenous obesity. Circulation 1965;32:740-5.

46. Alpert MA. Obesity cardiomyopathy: Pathophysiology and evolution of the clinical syndrome. Am J Med Sci 2001;321:225-36.

47. Pascual M, Pascual DA, Soria F, et al. Effects of isolated obesity on systolic and diastolic left ventricular function. Heart 2003;89:1152-6.

48. Berkalp B, Cesur V, Corapcioglu D, Erol C, Baskal N. Obesity and left ventricular diastolic dysfunction. Int J Cardiol 1995;52:23-6.

49. Peterson LR, Waggoner AD, Schechtman KB, et al. Alterations in left ventricular structure and function in young healthy obese women. J Am Coll Cardiol 2004;43:1399-404.

50. Kenchaiah S, Evans JC, Levy D, et al. Obesity and the risk of heart failure. N Engl J Med 2002;347:305-13.

51. Curtis JP, Selter JG, Wang Y, et al. The obesity paradox: Body mass index and outcomes in patients with heart failure. Arch Intern Med 2005;165:55-61.

52. Soth M, Otis J, Killian KJ. Body mass index, muscle strength, pulmonary impairment, and exercise capacity in COPD. Proc Am Thorac Soc 2005;2:529A. (Abst)

53. Weyman AE, Davidoff R, Gardin J, Ryan T, St John Sutton M, Weissman NJ. Echocardiographic evaluation of pulmonary artery pressure with clinical correlates in predominantly obese adults. J Am Soc Echocardiogr 2002;15:454-62.

54. Gibson GJ. Obesity, respiratory function and breathlessness. Thorax 2000;55(Suppl 1):41-4.

55. Bulpitt CJ, Palmer AJ, Battersby C, Fletcher AE. Association of symptoms of type 2 diabetic patients with severity of disease, obesity and blood pressure. Diabetes Care 1998;21:111-5.

56. Pankow W, Podszus T, Gutheil T, Penzel T, Peter JH, Von Wichert P. Expiratory flow limitation and intrinsic positive end-expiratory pressure in obesity. J Appl Physiol 1998;85:1236-43

57. Sahebjami H. Dyspnea in obese healthy men. Chest 1998;114:1373-7.

58. Ferretti A, Giampiccolo P, Cavalli A, Milic-Emili J, Tantucci C. Expiratory flow limitation and orthopnea in massively obese subjects. Chest 2001;119:1401-8.

59. Tantisiri KG, Weiss ST. Complex interactions in complex traits: Asthma and obesity. Thorax 2001;56(Suppl 2):64-74.

60. Chinn S. Obesity and asthma: Evidence for and against a causal relation. J Asthma 2003;40:1-16.

61. Braback L, Hjern A, Rasmussen F. Body mass index, asthma and allergic rhinoconjunctivitis in Swedish conscripts - A national cohort study over three decades. Respir Med 2005;99:1010-4.

62. Camargo CA, Weiss ST, Zhang S, Willett WC, Speizer FE. Prospective study of body mass index, weight change, and risk of adult-onset asthma in women. Arch Intern Med 1999;159:2582-8.

63. Litonjua AA, Sparrow D, Weiss ST. The $\mathrm{FEF}_{25-75} / \mathrm{FVC}$ ratio is associated with methacholine airway responsiveness. The normative aging study. Am J Respir Crit Care Med 1999;159:1574-9.

64. Boulet LP, Turcotte H, Boulet G, Simard B, Robichaud P. Deep inspiration avoidance and airway response to methacholine: Influence of body mass index. Can Respir J 2005;12:371-6

65. Shore SA, Fredberg JJ. Obesity, smooth muscle and airway hyperresponsiveness. J Allergy Clin Immunol 2005;115:925-7.

66. Sin DD, Jones RL, Man SF. Obesity is a risk factor for dyspnea but not for airflow obstruction. Arch Intern Med 2002;162:1477-81

67. Schachter LM, Salome CM, Peat JK, Woolcock AJ. Obesity is a risk for asthma and wheeze but not airway hyperresponsiveness. Thorax 2001;56:4-8

68. Sood A. Does obesity weigh heavily on the health of the human airway? J Allergy Clin Immunol 2005;115:921-4.

69. Landbo C, Prescott E, Lange P, Vestbo J, Almdal TP. Prognostic value of nutritional status in chronic obstructive pulmonary disease. Am J Respir Crit Care Med 1999;160:1856-61.

70. Marquis K, Debigare R, Lacasse Y, et al. Midthigh muscle cross-sectional area is a better predictor of mortality than body mass index in patients with chronic obstructive pulmonary disease. Am J Respir Crit Care Med 2002;166:809-13.

71. Oga T, Nishimura K, Tsukino M, Sato S, Hajiro T. Analysis of the factors related to mortality in chronic obstructive pulmonary disease. Role of exercise capacity and health status. Am J Respir Crit Care Med 2003;167:544-9.

72. Thomas PS, Cowen ER, Hulands G, Milledge JS. Respiratory function in the morbidly obese before and after weight loss. Thorax 1989;44:382-6.

73. Karason K, Lindroos AK, Stenlof K, Sjostrom L. Relief of cardiorespiratory symptoms and increased physical activity after surgically induced weight loss: Results from the Swedish Obese Subjects study. Arch Intern Med 2000;160:1797-802.

74. Sartorio A, Narici MV, Fumagalli E, Faglia G, Lafortuna CL. Aerobic and anaerobic performance before and after a short-term body mass reduction program in obese subjects. Diabetes Nutr Metab 2001;14:51-7. 


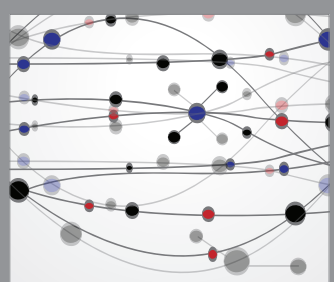

The Scientific World Journal
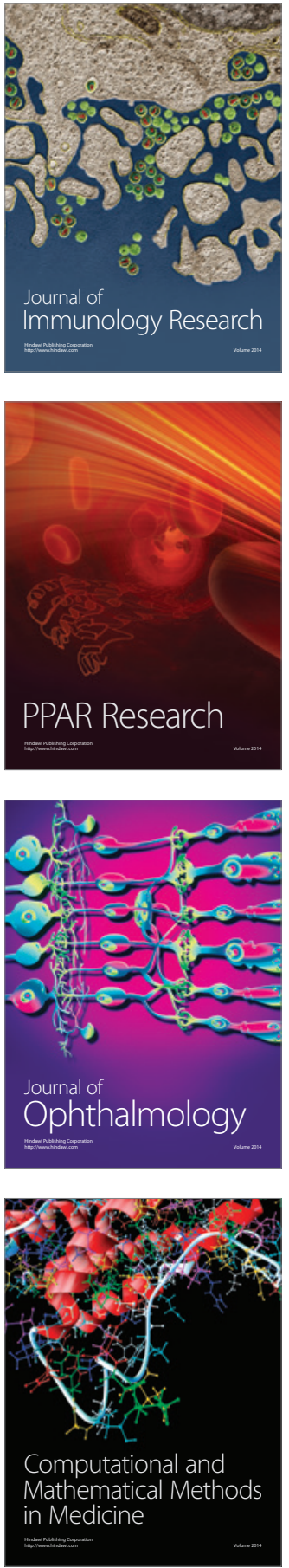

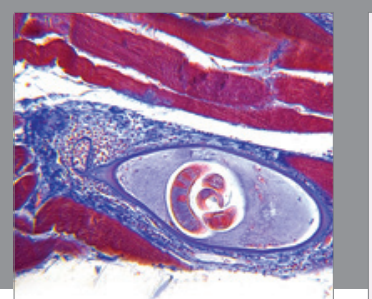

Gastroenterology Research and Practice

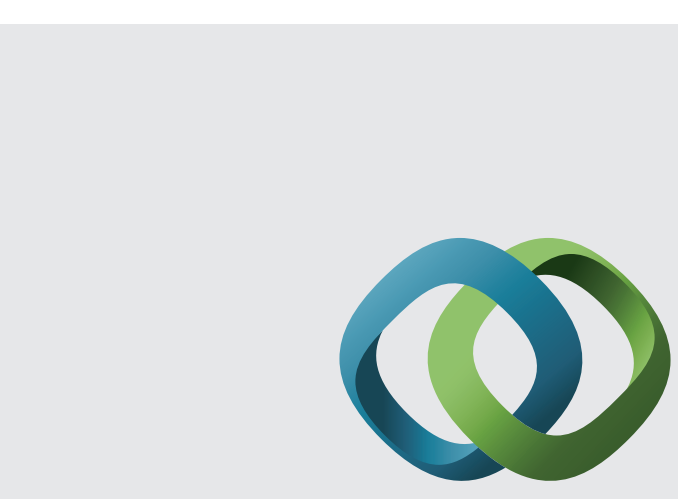

\section{Hindawi}

Submit your manuscripts at

http://www.hindawi.com
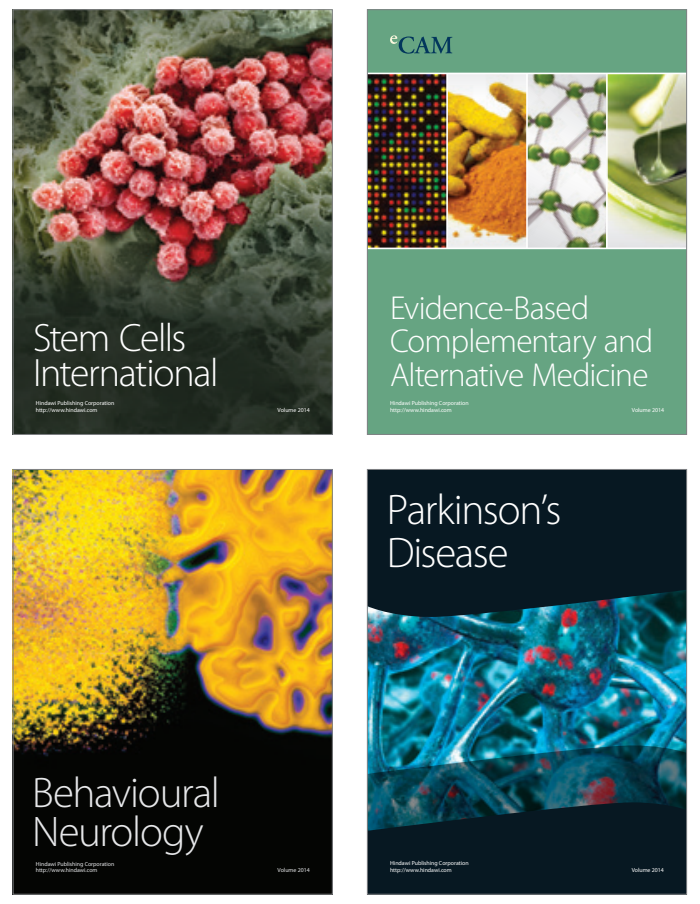
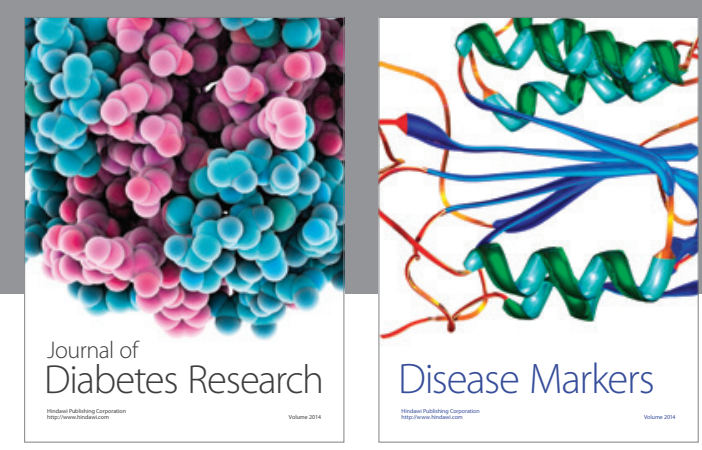

Disease Markers
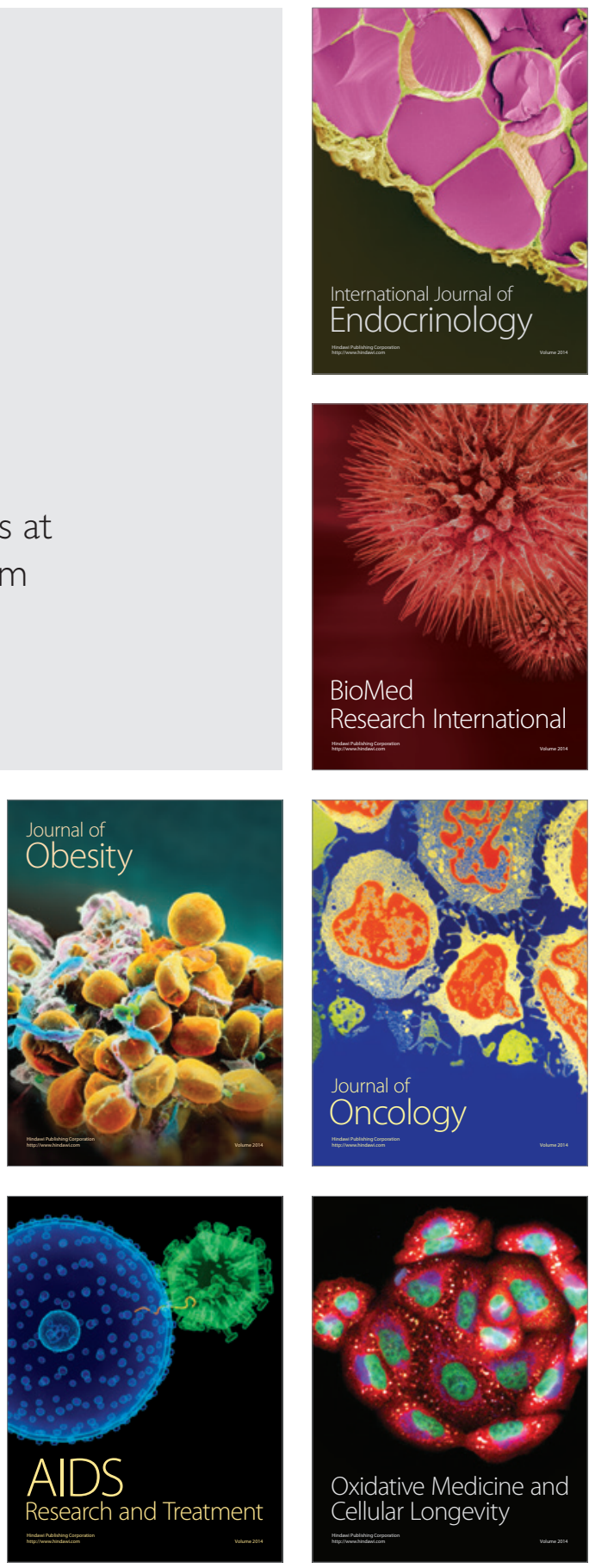